\title{
The Effectiveness of Hyperbaric Oxygen Therapy as Salvage Treatment for Sudden Sensorineural Hearing Loss: A Retrospective Study
}

\author{
Nasser Almutairi ${ }^{1}$, Ebraheem Alnofal ${ }^{1}$, Amani Algouhi ${ }^{2}$, Afnan S. Bamajboor ${ }^{3}$, Nabeel Alzaher ${ }^{4}$ \\ 1. Otolaryngology - Head and Neck Surgery, King Faisal Specialist Hospital \& Research Centre, Riyadh, SAU 2. \\ Otolaryngology - Head and Neck Surgery, Alfaisal University College of Medicine, Riyadh, SAU 3. Medicine, Alfaisal \\ University College of Medicine, Riyadh, SAU 4. Otolaryngology, King Faisal Specialist Hospital \& Research Centre, \\ Riyadh, SAU
}

Corresponding author: Nasser Almutairi, dr.nasser-20@hotmail.com

\section{Abstract \\ Background}

Sudden sensorineural hearing loss (SSNHL) is a medical emergency; its etiology is unknown in most cases, The treatment, in turn, is empiric and usually consists of various pharmacological agents, mainly steroids. Hyperbaric oxygen (HBO) therapy is used routinely as salvage therapy for refractory SSNHL. While several studies have demonstrated the effectiveness of HBO therapy as salvage treatment for refractory SSNHL, its results have varied among studies, and its efficacy is still unclear.

\section{Aim}

We aimed to stratify the effect of HBO therapy as salvage treatment after the failure of steroid therapy for SSNHL.

\section{Method}

This is a retrospective case series that involved eight SSNHL patients in the past three years at King Faisal Specialist Hospital \& Research Centre (KFSHRC) in Riyadh, Saudi Arabia. Patients' records were reviewed and statistical analysis was performed.

\section{Results}

Eight patients were included in this case series; six of them were males, and the mean age of all patients was $46.88 \pm 20.9$ years. One patient had herpes zoster as the cause of SSNHL and seven patients' disease was of unknown etiology. The mean period for the onset of disease was $4.12 \pm 2.17$ days. One patient was managed with intravenous dexamethasone and the other patients were managed with oral steroids, and all patients were then treated by HBO therapy. Of the patients, two showed significant improvement but the others did not. The cause of SSNHL, age of patients, HBO start and cessation, comorbidities, and disease onset did not affect the improvement in disease in patients (p: '0.05).

Review began 09/13/2020 Review ended 10/01/2020 Published 10/06/2020

\section{(c) Copyright 2020}

Almutairi et al. This is an open access article distributed under the terms of the Creative Commons Attribution License CC-BY 4.0., which permits unrestricted use, distribution, and reproduction in any medium, provided the original author and source are credited.

\section{Conclusion}

Moderate-to-severe cases of SSNHL can be improved by HBO treatment along with oral steroids, while this therapy was ineffective in severe and profound cases. No factors could be found to predict improvement in patients.

Categories: Otolaryngology

Keywords: ssnhl, hbo therapy, sudden hearing loss, steroids

\section{Introduction}

Sudden sensorineural hearing loss (SSNHL) is defined as sensorineural hearing loss to an extent of at least $30 \mathrm{~dB}$, involving not less than three successive frequencies that develop within 72 hours [1]. SSNHL symptoms usually occur suddenly and unilaterally within 24-72 hours [2]. Symptoms include dizziness and tinnitus that occur in $29-56 \%$ and $41-90 \%$ of patients, respectively [3-6]. SSNHL affects individuals of all ages, but it predominantly occurs in people between the fifth and sixth decade of their lives [7]. It affects almost 5 -20 per 10,000 individuals in the US [3,8]. Several pathologic processes have been proposed to be the possible causes of SSNHL, such as autoimmune reaction, viral infection, and circulatory disorders [9]. In the majority of SNHL patients, no specific factor could be identified as the cause of hearing loss; so it was identified as idiopathic $[3,4,10,11]$.

The rate of spontaneous recovery among SSNHL patients ranges from 25-89\% [12]. The recovery hearing 
threshold of patients with SSNHL may be either complete (return to the previous baseline), partial (more than $30 \mathrm{~dB}$ improvement), or none at all [7]. Several factors have been found to affect hearing recovery, such as the nature of the onset of hearing loss, the time of the onset of hearing loss, presence of vertigo, age, and frequencies affected [3]. There are different treatment regimens for SSNHL, and the most common one involves steroids. Other regimens may include vasodilators, carbogen therapy, antioxidants, and hyperbaric oxygen (HBO) therapy $[2,13]$. Steroids can be administrated either by intratympanic injection or systematically via intravenous or the oral route [2]. The recovery outcome rates have been found to be unsatisfactory as the recovery may occur in only $61 \%$ of patients [14]. Studies on most of these agents are rare [15]; steroid therapy has shown success in some studies [14,16]. However, other studies did not confirm this success $[13,16]$. Best results have been achieved when HBO therapy is started within two weeks of the onset in combination with steroids [17]; also, a combination of $\mathrm{HBO}$ with systemic steroids was found to be successful in patients with hearing loss of more than $90 \mathrm{~dB}$ [18]. Additionally, it was found that an improvement of threshold resulted from HBO therapy especially in those patients with low frequencies with otherwise therapy-refractory SSNHL [19]. The results of HBO therapy for SSNHL treatment vary among different studies. The purpose of this case series is to assess the effect of HBO therapy as salvage therapy after the failure of steroid therapy for SSNHL in patients at King Faisal Specialist Hospital \& Research Centre (KFSHRC).

\section{Materials And Methods}

\section{Subjects and study design}

This was a retrospective case series study that included eight patients who were treated at KFSHRC. These patients had SSNHL and underwent HBO therapy sessions as salvage treatment during the period 20152018; we planned to provide 20 to 30 sessions of therapy to these patients. The medical records of the patients were reviewed, and improvement in patients post-HBO therapy was assessed using pure tone audiometry (PTA). Approval from the institutional review board (IRB) was obtained before undertaking the study.

\section{Statistical analysis}

Data were analyzed using SPSS Statistics software version 16 (IBM, Armonk, NY). It entailed simple descriptive analysis in the form of numbers and percentages for qualitative variables and median and range for quantitative variables. The Mann-Whitney U test was used to compare quantitative variables between improved and non-improved patients, and Fisher-exact was used as a test of significance to compare qualitative variables. A p-value of $<0.05$ was considered to be statistically significant.

\section{Results}

The age range of patients was $23-76$ years with a mean \pm SD of $46.88 \pm 20.9$ years. There were six (75\%) men and two (25\%) women. There were four patients with comorbidities; one had asthma (12.5\%), one had diabetes mellitus (DM), one had hypertension (HTN) and an old cerebrovascular accident (CVA), and one patient had hypothyroidism and dyslipidemia. The cause of SSNHL was unknown in seven patients (87.5\%), and only one patient had SSNHL caused by herpes zoster in the form of meningitis. The range of onset duration was one to seven days with a mean \pm SD of $4.12 \pm 2.17$ days. The demographics and clinical characteristics of the patients are shown in Table 1. 


\section{Cureus}

Characteristics

N (\%)

Age (years)

Mean \pm SD

$46.88 \pm 20.9$

Median (range)

42 (23-76)

Sex

Female

Male

$6(75 \%)$

Comorbidity

None

Asthma

DM

HTN, old CVA

$1(12.5 \%)$

Hypothyroidism, dyslipidemia

Unknown

$1(12.5 \%)$

Herpes zoster

$4.12 \pm 2.17$

Mean \pm SD

$4(1-7)$

Median (range)

\section{TABLE 1: Demographics and clinical characteristics of patients}

SD: standard deviation; DM: diabetes mellitus; HTN: hypertension; CVA: cerebrovascular accident

Different symptoms were found among patients; three (37.5\%) patients suffered from tinnitus, two patients had vertigo, one suffered from otalgia, and only two patients did not experience any symptoms. Five patients were administered with oral steroids. Of them, four started HBO therapy within two weeks; two discontinued HBO therapy after 20 days, one after 16 days, and one after one day. The last patient who was administered with oral steroids started HBO therapy within one week and discontinued it after 15 days. Three patients received different regimens. One was administered with intravenous dexamethasone, and started $\mathrm{HBO}$ within two weeks and discontinued it after 20 days. One was administered with an oral steroid and antiviral drugs for herpes zoster, and started HBO therapy within two weeks and discontinued it after 37 days. The last patient received an oral steroid and intratympanic steroid injection, and started HBO after one week and continued for 30 days. Table 2 summarizes the patients' treatment regimen. 


\section{Cureus}

\begin{tabular}{|c|c|c|c|}
\hline Steroids & HBO onset & Patients, n (\%) & HBO cessation (days) \\
\hline Oral & Within 2 weeks & $4(50 \%)$ & $16,20,20,1$ \\
\hline Oral & After 1 week & $1(12.5 \%)$ & 15 \\
\hline Oral steroid and intratympanic steroid injection & After 1 week & $1(12.5 \%)$ & 30 \\
\hline Intravenous dexamethasone & Within 2 weeks & $1(12.5 \%)$ & 20 \\
\hline Oral and antiviral & Within 2 weeks & $1(12.5 \%)$ & 37 \\
\hline
\end{tabular}

\section{TABLE 2: Patients' regimen of steroids and HBO therapy}

HBO: hyperbaric oxygen

PTA was performed before and after the treatment (Table 3). Four (50\%) patients had moderate-to-severe SNHL; after treatment, one patient's case became mild-to-moderate, and only patients (25\%) showed improvement. Three (37.5\%) cases were profound and they did not show improvement after treatment. One patient (12.5\%) suffered from severe SNHL and showed no improvement after treatment.

\begin{tabular}{|c|c|c|c|}
\hline Betore PIA & After PTA & Patients, n (\%) & Outcome \\
\hline & & & 2 improved \\
\hline & & & 2 showed no improvement \\
\hline Profound & Profond & $3(37.5 \%)$ & 3 showed no improvement \\
\hline Severe & Severe & $1(12.5 \%)$ & 1 showed no Improvement \\
\hline
\end{tabular}

\section{TABLE 3: Clinical investigation and patient improvements}

PTA: pure tone audiometry; SNHL: sensorineural hearing loss

The influence of selected factors on patient recovery was investigated; however, none of them were found to be associated with improvements in patients. These factors included the cause of the disease, time of onset and cessation of $\mathrm{HBO}$, presence of comorbidities, age, the onset of the disease, associated symptoms, or degree of hearing loss (p: '0.05) (Table 4). 


\section{Cureus}

\begin{tabular}{|c|c|c|c|}
\hline Factors & Improved, $\mathrm{n}(\%) /$ median (range) $^{\star}$ & Not improved, n (\%)/median (range) ${ }^{*}$ & P-value ${ }^{\star \star}$ \\
\hline \multicolumn{4}{|l|}{ Cause } \\
\hline Unidentified & $2(28.6 \%)$ & $5(71.4 \%)$ & \multirow[t]{2}{*}{1} \\
\hline Herpes zoster & $0(0 \%)$ & $1(100 \%)$ & \\
\hline \multicolumn{4}{|l|}{ HBO onset } \\
\hline After 1 week; within 2 weeks & $1(50 \%) ; 1(16.7 \%)$ & $1(50 \%) ; 5(83.3 \%)$ & 0.46 \\
\hline \multicolumn{4}{|l|}{ Comorbidity } \\
\hline No & $1(25 \%)$ & $3(75 \%)$ & \multirow[t]{2}{*}{1} \\
\hline Yes & $1(25 \%)$ & $3(75 \%)$ & \\
\hline Age (years) & $55.6(45-66)$ & $35(23-76)$ & 0.6 \\
\hline Onset (days) & $4.5(2-7)$ & $4(1-7)$ & 0.8 \\
\hline Cessation (days) & $25(20-30)$ & $18(1-37)$ & 0.4 \\
\hline \multicolumn{4}{|l|}{ Associated symptoms } \\
\hline Yes & $1(50.0)$ & 1 (16.7) & \multirow[t]{2}{*}{0.464} \\
\hline No & $1(50.0)$ & $5(83.3)$ & \\
\hline \multicolumn{4}{|l|}{ Degree of hearing loss } \\
\hline Severe or profound & 0 & $5(83.3)$ & \multirow[t]{2}{*}{0.107} \\
\hline Mild to moderate & $2(100.0)$ & $1(16.7)$ & \\
\hline
\end{tabular}

\section{TABLE 4: Factors influencing patient improvement}

*n (\%): for qualitative variables; median (range): for quantitative variables. **Fisher's exact test

HBO: hyperbaric oxygen

\section{Discussion}

The present case series included eight patients; six of them were males and two were females. The age range of the patients was 23-76 years with a mean age of 46.88 years. Half of the patients did not suffer from any comorbidity; the range of the onset duration was one to seven days with a mean of 4.12 days. It has been reported previously that the incidence of SSNHL is found equally in males and females $[3,4,10,11]$. However, SSNHL in our case series was more dominant in males than in females. Different pathologic processes have been suggested to be the possible causes of SSNHL, including viral infections; however, in most cases, the cause remains unknown $[9,15]$. In the current case series, there were seven patients with unknown cause of SSNHL, while only one patient had a known cause, with herpes zoster being the cause of SSNHL occurrence. Seven patients in this case series were administrated oral steroids and only one patient was administrated intravenous dexamethasone. The patients were then started on HBO therapy; however, two patients who were administrated steroid therapy were also given other agents. An antiviral agent was administrated to one patient who had herpes zoster, and the other patient was managed with an intratympanic steroid injection in addition to oral steroids. It has been reported that the best results can be obtained by starting HBO therapy within two weeks in combination with steroids [17]. Six of our patients started the HBO therapy within two weeks, and only two patients started $\mathrm{HBO}$ after one week.

The duration of $\mathrm{HBO}$ administration ranged from 1-37 days. It was found that the administration of HBO therapy besides the primary conventional therapy improved outcomes of patients when started early [20,21]. The improvements in our patients were investigated; patients who had profound SSNHL (three patients) before treatment regimen did not show any improvements and their status remained profound. The same was found for the case that suffered severe SSNHL; the treatment did not lead to any improvement. There were four patients who suffered moderate-to-severe SSNHL before treatment, and after treatment, two patients improved and two did not. In Bal et al.'s case study, it was demonstrated that the combination of both intratympanic steroid and HBO therapy with oral steroids may enhance the efficiency of treatment and the patient can be rescued from cochlear implementation surgery [22]. Another case report by Imsuwansri et al. found that a patient with idiopathic SSNHL did not respond to intratympanic and systemic steroid 
treatment, but he recovered after HBO therapy [23]. One study [15] showed that using HBO as salvage therapy for SSNHL resulted in improvements in those with severe hearing loss, whereas patients with mild or moderate hearing loss can recover at low frequencies; however, we found the opposite in the current work. Another study [24] recommended HBO therapy for the treatment of SSNHL. In a prospective controlled study, it was found that significant improvements were obtained by the application of HBO therapy in patients whose corticosteroid treatment failed [23]. Another study supported the previous findings by suggesting HBO therapy for all patients who did not respond to conventional therapy, and the improvement rate was $46 \%$ among the study group [24]. It was reported that recovery may reach up to $61 \%$ among patients [14]; however, among our patients, only $25 \%$ have recovered (two patients). It is reported that there are several factors that impact hearing recovery, including hearing-loss severity, age at the time of the onset of hearing loss, and time between the onset of hearing loss and treatment [3]. However, in this case series, the improvements in patients were not affected by any of the following factors: the cause, start and cessation of HBO, presence of comorbidity, age, disease onset, associated symptoms, or degree of hearing loss. Another previous study has shown that hearing improvements were not associated with age [15], which is consistent with our findings.

\section{Conclusions}

Based on our findings, moderate-to-severe SSNHL cases can be improved with treatment by a combination of steroid and HBO therapy, while profound and severe cases showed no improvement. We could not identify any factor that influenced the improvements in our patients as there was no significant difference between patients who showed improvement and those who did not with respect to factors suggested by previous studies.

\section{Additional Information \\ Disclosures}

Human subjects: Consent was obtained by all participants in this study. Research Ethics Committee of KFSHRC issued approval 2191013. This study was approved by the Research Ethics Committee of KFSHRC. Animal subjects: All authors have confirmed that this study did not involve animal subjects or tissue. Conflicts of interest: In compliance with the ICMJE uniform disclosure form, all authors declare the following: Payment/services info: All authors have declared that no financial support was received from any organization for the submitted work. Financial relationships: All authors have declared that they have no financial relationships at present or within the previous three years with any organizations that might have an interest in the submitted work. Other relationships: All authors have declared that there are no other relationships or activities that could appear to have influenced the submitted work.

\section{Acknowledgements}

We thank Abdulelah Almutairi, for his efforts in editing the article.

\section{References}

1. Metrailer AM, Babu SC: Management of sudden sensorineural hearing loss . Curr Opin Otolaryngol Head Neck Surg. 2016, 24:403-406. 10.1097/MOO.0000000000000287

2. Lamm H, Müller-Kortkamp C, Warnecke A, Pohl F, Paasche G, Lenarz T, Stolle SR: Concurrent hyperbaric oxygen therapy and intratympanic steroid application as salvage therapy after severe sudden sensorineural hearing loss. Clin Case Rep. 2016, 4:287-293. 10.1002/ccr3.510

3. Byl FM Jr: Sudden hearing loss: eight years' experience and suggested prognostic table. Laryngoscope. 1984, 94:647-661. 10.1288/00005537-198405000-00014

4. Fetterman BL, Saunders JE, Luxford WM: Prognosis and treatment of sudden sensorineural hearing loss . Am J Otol. 1996, 17:529-536.

5. Huy PT, Sauvaget E: Idiopathic sudden sensorineural hearing loss is not an otologic emergency . Otol Neurotol. 2005, 26:896-902. 10.1097/01.mao.0000185071.35328.6d

6. Xenellis J, Karapatsas I, Papadimitriou N, Nikolopoulos T, Maragoudakis P, Tzagkaroulakis M, Ferekidis E: Idiopathic sudden sensorineural hearing loss: prognostic factors. J Laryngol Otol. 2006, 120:718-724. 10.1017/S0022215106002362

7. Kuhn M, Heman-Ackah SE, Shaikh JA, Roehm PC: Sudden sensorineural hearing loss: a review of diagnosis, treatment, and prognosis. Trends Amplif. 2011, 15:91-105. 10.1177/1084713811408349

8. Hughes GB, Freedman MA, Haberkamp TJ, Guay ME: Sudden sensorineural hearing loss. Otolaryngol Clin North Am. 1996, 29:393-405.

9. Chau JK, Lin JR, Atashband S, Irvine RA, Westerberg BD: Systematic review of the evidence for the etiology of adult sudden sensorineural hearing loss. Laryngoscope. 2010, 120:1011-1021. 10.1002/lary.20873

10. Nosrati-Zarenoe R, Arlinger S, Hultcrantz E: Idiopathic sudden sensorineural hearing loss: results drawn from the Swedish national database. Acta Otolaryngol. 2007, 127:1168-1175. 10.1080/00016480701242477

11. Shaia FT, Sheehy JL: Sudden sensori-neural hearing impairment: a report of 1,220 cases . Laryngoscope. 1976, 86:389-398. 10.1288/00005537-197603000-00008

12. Heiden C, Porzsolt F, Biesinger E, Höing R: Spontaneous remission of sudden deafness. (Article in German) . HNO. 2000, 48:621-623. 10.1007/s001060050626

13. Conlin AE, Parnes LS: Treatment of sudden sensorineural hearing loss: I. A systematic review . Arch Otolaryngol Head Neck Surg. 2007, 133:573-581. 10.1001/archotol.133.6.573 
14. Wilson WR, Byl FM, Laird N: The efficacy of steroids in the treatment of idiopathic sudden hearing loss. A double-blind clinical study. Arch Otolaryngol. 1980, 106:772-776. 10.1001/archotol.1980.00790360050013

15. Ajduk J, Ries M, Trotic R, Marinac I, Vlatka K, Bedekovic V: Hyperbaric oxygen therapy as salvage therapy for sudden sensorineural hearing loss. J Int Adv Otol. 2017, 13:61-64. 10.5152/iao.2017.3185

16. Moskowitz D, Lee KJ, Smith HW: Steroid use in idiopathic sudden sensorineural hearing loss . Laryngoscope. 1984, 94:664-666. 10.1288/00005537-198405000-00016

17. Goto F, Fujita T, Kitani Y, Kanno M, Kamei T, Ishii H: Hyperbaric oxygen and stellate ganglion blocks for idiopathic sudden hearing loss. Acta Otolaryngol. 1979, 88:335-342. 10.3109/00016487909137177

18. Murphy-Lavoie H, Piper S, Moon RE, Legros T: Hyperbaric oxygen therapy for idiopathic sudden sensorineural hearing loss. Undersea Hyperb Med. 2012, 39:777-792.

19. Liu SC, Kang BH, Lee JC, et al.: Comparison of therapeutic results in sudden sensorineural hearing loss with/without additional hyperbaric oxygen therapy: a retrospective review of 465 audiologically controlled cases. Clin Otolaryngol. 2011, 36:121-128. 10.1111/j.1749-4486.2011.02303.x

20. Muzzi E, Zennaro B, Visentin R, Soldano F, Sacilotto C: Hyperbaric oxygen therapy as salvage treatment for sudden sensorineural hearing loss: review of rationale and preliminary report. J Laryngol Otol. 2010, 124:e2. 10.1017/S0022215109992052

21. Fujimura T, Suzuki H, Shiomori T, Udaka T, Mori T: Hyperbaric oxygen and steroid therapy for idiopathic sudden sensorineural hearing loss. Eur Arch Otorhinolaryngol. 2007, 264:861-866. 10.1007/s00405-0070272-6

22. Bal KK, Ismi O, Bucioglu H, Vayısoğlu Y, Gorur K: Sudden sensorineural hearing loss in the only hearing ear: large vestibular aqueduct syndrome. Case Rep Otolaryngol. 2016, 2016:8909124. 10.1155/2016/8909124

23. Imsuwansri T, Poonsap P, Snidvongs K: Hyperbaric oxygen therapy for sudden sensorineural hearing loss after failure from oral and intratympanic corticosteroid. Clin Exp Otorhinolaryngol. 2012, 5:S99-S102. 10.3342/ceo.2012.5.S1.S99

24. Živaljević Z, Živić L, Mihailović N, Živković M, Vorkapić B, Baletić N: Treatment of sudden sensorineural hearing loss with hyperbaric oxygenation: our experience. Vojnosanit Pregl. 2016, 74:156-160. 10.2298/VSP150529168Z 